\title{
SIMULAÇÃO: ASPECTOS CONCEITUAIS
}

\author{
SIMULATION: CONCEPTUALISSUES
}

Antonio Pazin Filho', Minna Moreira Dias Romano²

\begin{abstract}
'Docente. ${ }^{2}$ Médica Assistente. Divisão de Cardiologia. Departamento de Clínica Médica. Faculdade de Medicina de Ribeirão Preto - USP CorResPondêncIA: Antonio Pazin Filho (apazin@fmrp.usp.br). Centro de Estudos de Emergências em Saúde - CEES. Rua Bernardino de Campos, 1000 - 14015-030 - Ribeirão Preto - SP.
\end{abstract}

Pazin Filho A, Romano MMD. Simulação: aspectos conceituais. Medicina (Ribeirão Preto) 2007;40 (2): 167-70.

Resumo: A simulação exige a elaboração do conteúdo a ser transmitido, envolvendo a decomposição das tarefas a serem executadas em seus diversos componentes que serão estruturados em forma hierarquizada. Este conteúdo deve ser apresentado ao aluno através de quatro princípios básicos: exposição, seqüência, feed-back e repetição.

Descritores: Simulação. Educação Médica.

\section{1- INTRODUÇÃO}

Basicamente a técnica de Simulação exige dois componentes. O primeiro é a elaboração do conteúdo a ser transmitido de modo claro e seqüencial, com pontos muito bem estabelecidos. O segundo é a técnica de como este conteúdo é transmitido. Este artigo irá abordar os dois componentes, ilustrando com exemplos dos cursos de Suporte de Vida.

\section{2- ELABORAÇÃO}

As técnicas de aprendizado baseado em experiências (Simulação e Demonstração) têm como objetivo básico o ensino de habilidades ${ }^{1}$. Para que uma habilidade possa ser transmitida, é necessário primeiramente que ela seja decomposta em seus componentes básicos. Isto favorece que o instrutor transmita esta habilidade de modo sistematizado e identifique mais facilmente os erros dos alunos, favorecendo intervenções corretivas ${ }^{1,2,3}$. Também permite ao aluno o aprendizado de modo padronizado, favorecendo um aspecto fundamental da técnica que é a repetição ${ }^{4}$.
Tomemos como exemplo a massagem cardíaca externa para ilustrar os conceitos necessários. Vamos nos ater na técnica de massagem, sem nos preocuparmos no momento em quando ela dever ser iniciada, interrompida ou intercalada com a respiração boca-a-boca. Para motivos do nosso exemplo, devemos transmitir o conhecimento de como a massagem deve ser feita. O primeiro passo é identificar quais são os componentes que devem ser ensinados, que estão ilustrados na Figura 1, para o exemplo em questão.

Um componente deve ser algo fundamental para que a técnica seja executada de modo correto. A definição do que é correto pode ser pautada na facilidade, reprodutibilidade e redução de possíveis efeitos lesivos para quem executa e, nos casos em que se aplica o procedimento em alguém, no paciente em questão. Esta definição deve ser de ampla aceitação, o que pode ser conseguido por diversas formas. No exemplo dos cursos de Suporte de Vida, isto é conseguido através de estudos científicos revisados sistematicamente por comissões de especialistas periodicamente. Isto garante a uniformidade e a respeitabili- 


\section{1- Posicionamento adequado da ví- tima \\ 2- Posicionamento do socorrista \\ 3- Colocação das mãos sobre o tó- rax da vítima de forma adequada \\ Cardíaca \\ Externa}

Figura 1: A Massagem Cardíca Externa decomposta nos seus diversos componentes.

dade do que está sendo ensinado ${ }^{5,6,7}$. Nas técnicas de ensino que focam principalmente o ensino de habilidades, a ênfase deve ser no procedimento e não em pontos controversos, que são melhor ilustrados por técnicas de ensino para cognição, como a aula teórica ${ }^{8}$.

Um segundo ponto que deve ser ressaltado na definição fornecida para componente é "fundamental para que a técnica seja executada", ou seja, o componente deve ser um ponto de estrangulamento. O aluno não conseguirá executar o procedimento ou o executará de modo inadequado se não vencer esta etapa. Isto implica que o componente tenha, por definição, uma ordenação, ou seja, ele deve ser parte de uma seqüência pré-estabelecida ${ }^{1,9,10}$.

Estes conceitos são melhor ilustrados graficamente na forma de um fluxograma. A Figura 2 ilustra os três primeiros componentes da Figura 1 na forma de fluxograma. Ele se inicia com o primeiro componente que é o posicionamento adequado da vítima. Se a vítima não estiver deitada em decúbito dorsal numa superfície rígida, a massagem será ineficaz, pois ao invés de ser comprimido contra a coluna, o coração irá acompanhar o deslocamento do corpo para trás, empurrado pela manobra. Ao observarmos o aluno, poderemos verificar se ele posicionou ou não a vítima, ou seja, a resposta é do tipo dicotomizada - sim ou não. Caso ele execute esta etapa (sim), pode prosseguir para a outra. Caso contrário (não), isto nos gerará a informação de que ele não compreende a importância daquele ponto e podemos tomar medidas para reforçar estes conceitos.

Embora a Figura 2 ilustre apenas situações de resposta dicotomizada, como é comum nas habilidades psicomotoras, estas respostas podem ser de múltiplas escolhas e cada uma destas categorias pode levar a um outro tipo de fluxograma. Isto é comum na discussão de habilidades mais intelectualizadas, como no raciocínio clínico.

\section{Posicionamento adequa do da vítima?}

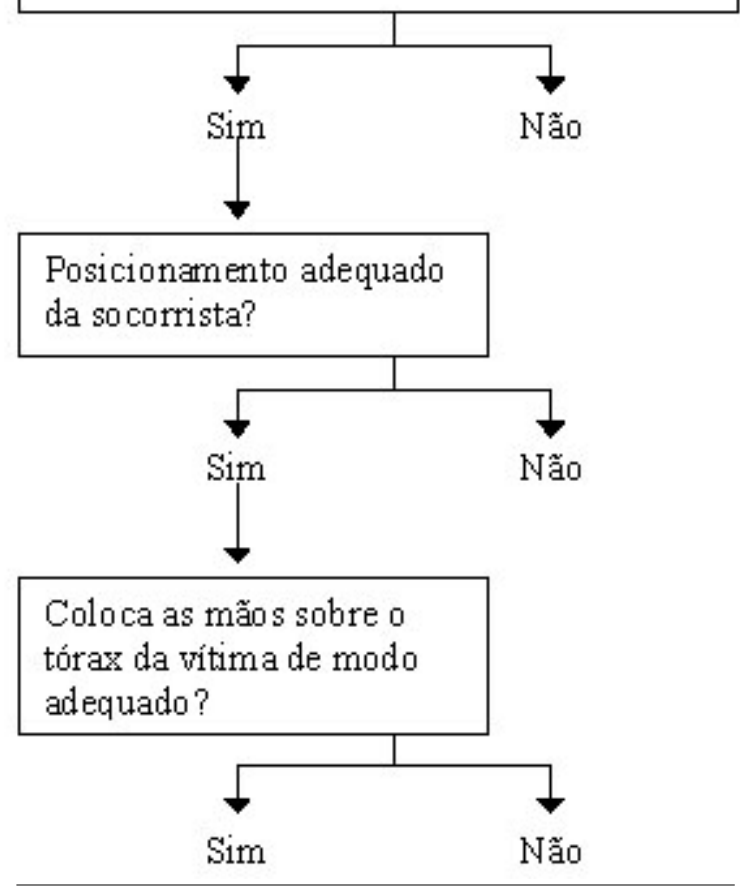

Figura 2: Os três primeiros componentes da Massagem Cardíaca Externa representados na forma de um fluxograma.

Mesmo que se leve em consideração toda a evidência científica disponível para a elaboração dos diversos componentes de uma tarefa, sempre haverá pontos deficientes na informação que tornem a realização de um componente menos absoluta do que um outro. Assim, por exemplo, a informação disponível para a freqüência das compressões (item 5, Figura 1) é ampla, enquanto para a avaliação de eficácia da técnica (item 7, Figura 1) já é deficitária. Este conhecimento é muito importante para o instrutor, como será discutido no capítulo sobre aspectos técnicos de simulação, que deve entender que cada um dos pontos ilustrados no fluxograma podem ter graus diferentes de importância na elaboração da atividade. Esta é uma das características que torna a condução de situações 
de simulação muito dependente da presença de um instrutor, que garante o fluxo do aprendizado e fornece explicações contextualizadas.

\section{3- APLICAÇÃO}

Após a elaboração do conteúdo, devemos agora nos focar no modo em como ele é transmitido. A simulação envolve uma atividade de interação entre o aluno e o simulador, acompanhada ou gerenciada por um instrutor, que será de intensidade crescente à medida em que se utilizem técnicas mais elaboradas de simulação (Vide capítulo 1). Existem quatro princípios importantes para que esta interação aconteça de modo adequado: exposição, seqüencia, feed-back e repetição. Estes princípios estão resumidos na Tabela I.

O primeiro componente a ser considerado é a exposição da situação a ser apresentada ao aluno. Ela deve apresentar o problema a ser resolvido de modo claro, permitindo ao aluno identificar qual é o tipo de tarefa que se espera que ele desenvolva. Além da clareza, é importante que seja sucinta e objetiva, de modo que o aluno seja rapidamente conduzido para uma atitude ativa no processo, o que é fundamental para o sucesso da atividade. Isto pode ser feito pelo instrutor ou pode estar escrito em cartazes, na dependência do contexto em que se utilize o método. No exemplo da massagem cardíaca externa, uma forma de se expor o problema seria: "Este paciente foi encontrado desacordado em decúbito ventral na via pública, sendo constatado que ele não responde, não respira e não tem pulso".

A decomposição do conteúdo a ser transmitido faz com que uma grande quantidade de componentes seja gerada, sendo que se a transmissão desta informação não for dosada, isto restringirá sobremaneira a capacidade de retenção do aluno ${ }^{4}$. Isto é evitado ao se adotar uma seqüência de complexidade crescente. Na elaboração da atividade, o instrutor deve elaborar casos objetivos que abordem uma quantidade pré-estabelecida de informação, incorporando novos conceitos à medida em que o aluno ou grupo de alunos complete a tarefa anterior. No exemplo em questão, a primeira situação pode abordar o procedimento da massagem. Caso ele seja executado de modo adequado, uma segunda situação poderia agora concatenar a realização desta massagem com a respiração bocaà-boca. Completada esta fase, a concatenação destas duas atividades na presença de dois socorrista pode ser explorada e assim sucessivamente.

O sucesso da transmissão da informação reside na interação contínua entre o aluno e o simulador, cuja manutenção é uma das funções do instrutor. $\mathrm{O}$ instrutor deve estar atento para cada ação do aluno, sendo responsável por fornecer feed-back, que deve valorizar os componentes completados adequadamente e salientar os pontos que necessitam de mais atenção ${ }^{4}$. Embora este feed-back caiba ao instrutor na maior parte das vezes, ele pode ser fornecido pelos próprios alunos que executaram a tarefa ou pelos de-

Tabela I: Etapas e princípios a serem respeitados nas situações de simulação

\begin{tabular}{|c|c|c|}
\hline Etapas & Princípios & Considerações \\
\hline \multirow[t]{2}{*}{ Elaboração } & Decomposição & $\begin{array}{l}\text { As tarefas a serem executadas são decompostas em componentes. } \\
\text { Componentes são pontos críticos que devem ser cumpridos para a correta } \\
\text { execução da atividade. }\end{array}$ \\
\hline & Ordenação & $\begin{array}{l}\text { Os componentes devem ter uma seqüência, geralmente ilustrada de modo } \\
\text { gráfico em fluxogramas. }\end{array}$ \\
\hline \multirow[t]{4}{*}{ Aplicação } & Exposição & $\begin{array}{l}\text { Descrição da situação a ser avaliada e resolvida pelo aluno. Deve ser clara, } \\
\text { sucinta e objetiva. }\end{array}$ \\
\hline & Seqüência & Complexidade crescente. \\
\hline & Feed-back & $\begin{array}{l}\text { Complementação da informação transmitida caracterizando uma reação por } \\
\text { parte do instrutor para uma ação do aluno. }\end{array}$ \\
\hline & Repetição & $\begin{array}{l}\text { Oferecer oportunidade de repetição exaustiva das etapas completadas a } \\
\text { cada nova exposição. }\end{array}$ \\
\hline
\end{tabular}


mais componentes do grupo (caso a atividade envolva um grupo). Existem diversas técnicas para fornecer feed-back, que dependem em muito do tipo de simulação que está sendo executado. As técnicas mais utilizadas no contexto de simulação de alta elaboração, como na utilização de manequins serão descritas no capítulo sobre aspectos técnicos.

O último componente que deve ser mantido em mente no processo de transmissão é a repetição. A retenção da informação transmitida é amplificada pelo processo exaustivo de repetição. Este princípio está intimamente relacionado ao princípio de sequiência anteriormente descrito, pois na elaboração dos casos a serem apresentados, pode-se incluir situações que favoreçam a prática do que foi discutido anteriormente. Assim, no exemplo da massagem cardíaca, ao se incorporar a concatenação com a respiração boca-àboca, além de se oferecer uma nova informação, há a possibilidade de se praticar a execução da massagem cardíaca. Este princípio é o mais comumente omitido por instrutores no processo de simulação. Ao elaborar a atividade, é comum que os instrutores tenham uma lista de objetivos a serem cobertos em um tempo de atividade pré-determinado, o que implica muitas vezes que se direcione o aluno rapidamente para uma nova situação, pulando etapas que já foram cobertas em situações anteriores. Nunca se deve esquecer que o objetivo da simulação é a prática da atividade e nenhuma oportunidade de prática deve ser desperdiçada. A cuidadosa elaboração da atividade pode garantir que os dois objetivos sejam cumpridos.

Em resumo, a simulação exige a elaboração do conteúdo a ser transmitido, envolvendo a decomposição das tarefas a serem executadas em seus diversos componentes que serão estruturados em forma hierarquizada. Este conteúdo deve ser apresentado ao aluno através de quatro princípios básicos: exposição, seqüência, feed-back e repetição.

Pazin Filho A, Romano MMD. Simulation: conceptual issues. Medicina (Ribeirão Preto) 2007;40 (2): 167-70.

Abstract: Simulation demands the elaboration of the information to be transmitted, including decomposing the task in several components that should obey sequency. The information should be presented respecting four basic principles: exposition, sequence, feed-back and repetition.

Keywords: Simulation. Education, Medical.

\section{REFERÊNCIAS}

1 - Galbraith MW. Adult learning methods: a guide for effective instruction. 1th. ed. Malabar (FL): Robert E. Krieger Publishing; 1990 .

2 - Issenberg SB, McGaghie WC, Hart IR, Mayer JW, Felner JM, Petrusa ER et al. Simulation technology for health care professional skills training and assessment. JAMA 1999;282(9):861-6.

3 - Pazin Filho A. Interação com a platéia. Medicina (Ribeirão Preto) $2007 ; 40(1): 42-50$

4 - Pazin Filho A. Características do aprendizado do adulto. Medicina (Ribeirão Preto) 2007;40(1):7-16.

5 - Morley PT, Zaritsky A. The evidence evaluation process for the 2005 International Consensus Conference on cardiopulmonary resuscitation and emergency cardiovascular care science with treatment recommendations. Resuscitation 2005;67(2-3):167-70.
6 - Nolan JP, Hazinski MF, Steen PA, Becker LB. Controversial Topics from the 2005 International Consensus Conference on cardiopulmonary resuscitation and emergency cardiovascular care science with treatment recommendations. Resuscitation 2005;67(2-3):175-9.

7 - White RD. 2005 American Heart Association Guidelines for Cardiopulmonary Resuscitation: physiologic and educational rationale for changes. Mayo Clin Proc 2006;81(6):736-40.

8 - Pazin Filho A. Aula teórica: quando utilizar? Medicina (Ribeirão Preto) 2007;40(1):3-6.

9 - Moorthy K, Munz Y, Sarker SK, Darzi A. Objective assessment of technical skills in surgery. BMJ 2003;327(7422):1032-7.

10 - Rogers PL. Simulation in medical students critical thinking. Crit Care Med 2004;32(Suppl. 2):S70-1. 